\title{
Hoveniae Semen Seu Fructus Ethanol Extract Exhibits Anti-Inflammatory Activity via MAPK, AP-1, and STAT Signaling Pathways in LPS-Stimulated RAW 264.7 and Mouse Peritoneal Macrophages
}

\author{
Yun Hee Jeong $\mathbb{D}$, You-Chang Oh $(\mathbb{D}$, Won-Kyung Cho $\mathbb{D}$, Nam-Hui Yim $\mathbb{D}$, and Jin Yeul Ma $\mathbb{D}$ \\ Korean Medicine (KM)-Application Center, Korea Institute of Oriental Medicine, 70, Cheomdanro, Dong-gu, \\ Daegu 41062, Republic of Korea \\ Correspondence should be addressed to Jin Yeul Ma; jyma@kiom.re.kr
}

Received 11 April 2019; Revised 16 June 2019; Accepted 8 July 2019; Published 4 September 2019

Academic Editor: Tomasz Brzozowski

Copyright (C) 2019 Yun Hee Jeong et al. This is an open access article distributed under the Creative Commons Attribution License, which permits unrestricted use, distribution, and reproduction in any medium, provided the original work is properly cited.

\begin{abstract}
Hoveniae semen seu fructus (HSF, fruit and seed of Hovenia dulcis Thunb) is an important traditional herbal medicine and food supplement in East Asia for the treatment of liver diseases, alcohol poisoning, obesity, allergy, and cancer. HSF has also been reported to have anti-inflammatory activity, but the cellular mechanism of action is not fully understood. We assessed the antiinflammatory properties of an HSF ethanol (HSFE) extract and explored its precise mechanism. The ability of HSFE to suppress inflammatory responses was investigated in a murine macrophage cell line, RAW 264.7, and mouse primary macrophages. Secretions of NO, proinflammatory cytokines, inflammatory factors, and related proteins were measured using the Griess assay, ELISA, Western blot analysis, and real-time PCR, respectively. In addition, the main components of HSFE were analyzed by HPLC, and their anti-inflammatory activity was confirmed. Our results showed that pretreatment of HSFE markedly reduced the expression of NO and iNOS without causing cytotoxicity and significantly attenuated secretion of proinflammatory cytokines, including TNF- $\alpha$, IL-6, and IL- $1 \beta$. In addition, HSFE strongly suppressed phosphorylation of MAPK and decreased the activation of AP-1, JAK2/STAT, and NF- $\kappa$ B in LPS-stimulated RAW 264.7 cells in a concentration-dependent manner. Furthermore, HSFE strongly suppressed the inflammatory cytokine levels in mouse peritoneal macrophages. Also, as a result of HPLC analysis, three main components, ampelopsin, taxifolin, and myricetin, were identified in the HSFE extract, and each compound effectively inhibited the secretion of inflammatory mediators induced by LPS. These findings show that HSFE exerts anti-inflammatory effects by suppressing the activation of MAPK, AP-1, JAK2/STAT, and NF- $\kappa$ B signaling pathways in LPS-stimulated macrophages. In addition, the anti-inflammatory efficacy of HSFE appears to be closely related to the action of the three main components. Therefore, HSFE appears to be a promising candidate for the treatment of inflammatory diseases.
\end{abstract}

\section{Introduction}

The inflammatory response in the body is a defense mechanism against potentially harmful stimuli, such as injury, viral or microbial infection, and irritants $[1,2]$. These inflammatory responses are involved in the activation of immune cells, such as macrophages. Macrophages have an essential role in modulating innate immune responses and inflammation [3]. During the inflammation process, lipopolysaccharide- (LPS-) stimulated macrophages secrete other proinflammatory factors, such as nitric oxide $(\mathrm{NO})$, prostaglandin $\mathrm{E}_{2}\left(\mathrm{PGE}_{2}\right)$, and cytokines, including tumor necrosis factor- (TNF-) $\alpha$, interleukin- (IL-) 6, and IL-1 $\beta$ [4]. LPS, known as endotoxins from the outer membranes of gram-negative bacteria, act on the toll-like receptor 4- (TLR4-) signaling pathway and elicit strong immune responses. The TLR4-signaling pathway is directly linked to the phosphorylation of the mitogenactivated protein kinase (MAPK) intercellular signaling pathway [5]. The three representative families of MAPK have been identified, including extracellular signal-regulated kinase (ERK), c-Jun $\mathrm{NH}_{2}$-terminal kinase (JNK), and p38, which also regulate immune-related cytotoxic mediators 
[6]. Upon stimulation by LPS, activated MAPKs in turn mediate several signal transducers, including nuclear factor(NF-) $\kappa \mathrm{B}$ and activator protein- (AP-) 1 [7]. The transcription factors $\mathrm{NF}-\kappa \mathrm{B}$ and $\mathrm{AP}-1$ are closely involved in the regulation of proinflammatory mediators, such as TNF, IL6 , IL-1 $\beta$, and inducible nitric oxide synthase (iNOS) [8]. Additionally, the Janus kinase (JAK)/signal transducer and activator of transcription (STAT) cascade is another critical signaling pathway that has an important role in immune responses and inflammation via the release of proinflammatory cytokines and growth factors [9]. Accordingly, inhibiting the MAPK, AP-1, and JAK/STAT signaling pathways can be important and effective strategies for treating inflammatory disease.

Hovenia dulcis Thunb is a well-known oriental raisin tree in East Asia that has traditionally been used to treat liver diseases, alcohol poisoning, obesity, allergy, and cancer [10-12]. A previous study showed that Hovenia dulcis Thunb extract had anti-inflammatory activity by inhibiting the NF- $\kappa \mathrm{B}$ pathway [13]. However, other signaling pathway mechanisms of action have not yet been investigated. Therefore, this study investigated whether hoveniae semen seu fructus ethanol (HSFE) extract exerts anti-inflammatory effects on LPSstimulated macrophage RAW 264.7 cells via the regulation of the MAPK, AP-1, and JAK/STAT signaling pathways. In addition, it was confirmed again whether HSFE pretreatment inhibited the activation of NF- $\kappa \mathrm{B}$ by LPS. We also investigated the anti-inflammatory effect of HSFE on LPSstimulated mouse primary macrophages.

\section{Materials and Methods}

2.1. Materials and Reagents. Dulbecco's Modified Eagle Medium (DMEM), fetal bovine serum (FBS), and antibiotics were obtained from HyClone (Logan, UT, USA). LPS, dexamethasone (Dex), bovine serum albumin (BSA), dimethyl sulfoxide (DMSO), and red blood cell (RBC) lysis buffer were purchased from Sigma-Aldrich (St. Louis, MO, USA). Enzyme-linked immunosorbent assay (ELISA) antibody sets were obtained from eBioscience (San Diego, CA, USA). Cell culture dishes and plates were purchased from SPL Life Sciences (Pocheon, Korea). A cell-counting kit (CCK) was obtained from Dojindo Molecular Technologies Inc. (Kumamoto, Japan). Various primary antibodies and horseradish peroxidase- (HRP-) conjugated secondary antibodies were purchased from Cell Signaling Technology Inc. (Boston, MA, USA) and Santa Cruz Biotechnology Inc. (Santa Cruz, CA, USA). An RNA extraction kit was obtained from iNtRON Biotechnology (Daejeon, Korea). DNA-synthesizing kits and an AccuPower ${ }^{\circledR}$ 2X GreenStar qPCR (quantitative polymerase chain reaction) Master Mix were obtained from Bioneer (Daejeon, Korea). Oligonucleotide primers for real-time reverse transcription-polymerase chain reaction (real-time PCR) were synthesized by Bioneer.

2.2. Preparation of HSFE. HSF was purchased as a dried herb from Yeongcheonhyundai Herbal Market (Yeongcheon, Korea) and identified by Prof. KiHwan Bae, Chungnam National University, Korea. All voucher specimens were deposited in an herbal bank at the KM-Application Center, Korea Institute of Oriental Medicine (voucher number: E126). The dried herb (30.0 g) was extracted with $390 \mathrm{~mL}$ of $70 \%$ ethanol in a $40^{\circ} \mathrm{C}$ shaking incubator $(100 \mathrm{rpm})$ for $24 \mathrm{~h}$. The extract was filtered through a $150 \mathrm{~mm}$ filter paper (Whatman, Piscataway, NJ, USA) and concentrated using a rotary vacuum evaporator (Buchi, Tokyo, Japan). Samples were then freeze dried and kept in desiccators at $-20^{\circ} \mathrm{C}$ before use. The sample yield was $4.6780 \%$.

2.3. Cell Culture and Drug Treatment. Murine macrophage RAW 264.7 cells were obtained from the Korea Cell Line Bank (KCLB, Seoul, Korea) and grown in complete DMEM. The cells were then incubated with humidified $5 \% \mathrm{CO}_{2}$ at $37^{\circ} \mathrm{C}$ [14]. To stimulate the cells, $200 \mathrm{ng} / \mathrm{mL}$ LPS [14] was added at the indicated periods in the presence or absence of HSFE $(10,30$, or $50 \mu \mathrm{g} / \mathrm{mL})$.

2.4. Cell Viability. Cytotoxicity induced by HSFE was analyzed using a CCK. First, RAW 264.7 macrophages were seeded into 96-well plates at a density of $5 \times 10^{4}$ cells/well. After $18 \mathrm{~h}$ incubation, HSFE was added to the cells, which were incubated for $48 \mathrm{~h}$ at $37^{\circ} \mathrm{C}$ with $5 \% \mathrm{CO}_{2}$ [15]. Treatment of CCK solution, incubation time, and analysis method were performed according to a previous study with some modifications [15].

2.5. Determination of NO Production. NO production was analyzed by measuring the nitrite levels in the supernatants of cultured macrophages. RAW 264.7 macrophages $\left(5 \times 10^{4}\right.$ cells/well $)$ were plated, incubated with HSFE, and stimulated with LPS for $24 \mathrm{~h}$. Griess reagent treatment and the analysis method were performed according to a previous report [16]. The concentration of nitrite was calculated using sodium nitrite as the standard.

2.6. Cytokine Determination. To determine the effects of HSFE on production of proinflammatory cytokines, cytokine production was measured using ELISA. For ELISA, $2.5 \times 10^{5}$ RAW 264.7 macrophages/well were seeded into 24-well plates and incubated overnight. The cells were pretreated with various concentrations of HSFE for $1 \mathrm{~h}$ and further challenged with LPS for an additional $24 \mathrm{~h}$ at $37^{\circ} \mathrm{C}$ with $5 \% \mathrm{CO}_{2}$ [17]. The levels of cytokines in the supernatants were measured using ELISA antibody sets according to a previous method [17].

2.7. Preparation of Whole Cell, Cytosolic, and Nuclear Extracts. To obtain whole cell lysates, pellets were resuspended in a radioimmunoprecipitation assay (RIPA) lysis buffer (Millipore, Bedford, MA, USA) containing protease and phosphatase inhibitors. Cytosolic and nuclear fractions were isolated by using NE-PER ${ }^{\mathrm{TM}}$ nuclear and cytoplasmic extraction reagents (Thermo Scientific, Rockford, IL, USA) according to the procedure described by the manufacturer. The fractions were stored at $-80^{\circ} \mathrm{C}$ before use.

2.8. Western Blot Analyses. Western blot analyses were performed to evaluate the effects of HSFE on the expression of each protein in the whole cell, cytosol, or nucleus. The cells 
were pretreated with HSFE and stimulated with LPS for the indicated times. After incubation, the cells were collected via scrapping and washed twice with ice-cold phosphatebuffered saline (PBS). Total protein was determined using a Bradford reagent (Bio-Rad, Hercules, CA, USA). Detailed methods and conditions of the protein analysis were followed with reference to a past study [15]. The information about the various primary and secondary antibodies used is listed in Table 1. Specific proteins were detected using the SuperSignal West Femto Chemiluminescent Substrate (Thermo Scientific). Protein levels were quantified using a Chemi$\operatorname{Doc}^{\mathrm{TM}}$ Touch Imaging System (Bio-Rad).

2.9. RNA Extraction and Real-Time PCR. Total cellular RNA was isolated using an easy-BLUE ${ }^{\mathrm{TM}}$ RNA extraction kit (iNtRON Biotechnology) according to the manufacturer's instructions. Total RNA ( $1 \mu \mathrm{g})$ was reverse transcribed into cDNA using an AccuPower ${ }^{\circledR}$ CycleScript RT PreMix (Bioneer). The oligonucleotide primers for real-time PCR used with mouse macrophage cDNA are listed in Table 2. The reactions were performed in triplicate, with a $20 \mu \mathrm{L}$ total volume: $0.3 \mu \mathrm{M}$ final concentrations of each primer, $10 \mu \mathrm{L}$ of AccuPower ${ }^{\circledR}$ 2X GreenStar qPCR Master Mix (Bioneer), and $2 \mu \mathrm{L}$ template DNA. The following PCR conditions were applied: TNF- $\alpha$, IL-6, IL- $1 \beta$, iNOS, cyclooxygenase- (COX-) 2 , heme oxygenase- 1 , and $\beta$-actin and 40 cycles at $94^{\circ} \mathrm{C}$ for $15 \mathrm{~s}$ and $60^{\circ} \mathrm{C}$ for $1 \mathrm{~min}$ [14]. The amplification and analyses were performed using a QuantStudio 6 Flex Real-time PCR System (Thermo Scientific). Samples were compared using the relative $C_{T}$ method. The fold increase or decrease in gene expression was determined relative to a blank control after normalization to the $\beta$-actin gene using $2^{-\Delta \Delta \mathrm{C}_{\mathrm{T}}}$ [14].

2.10. Peritoneal Macrophage Isolation and Cell Culture. Male $\mathrm{BALB} / \mathrm{c}$ mice $(25 \pm 3 \mathrm{~g})$ were obtained from Samtako BioKorea (Osan, Korea). The mice were inoculated with $300 \mu \mathrm{L}$ of sterile $3 \%$ sodium thioglycolate (Sigma-Aldrich, St. Louis, MO, USA). All mice were housed five per cage at room temperature with a $12 \mathrm{~h}: 12 \mathrm{~h}$ light/dark cycle; food (SCF Co. Ltd., Korea) and water were provided ad libitum. After 3 days, the animals were euthanized and macrophages were harvested by washing their peritoneal cavity with $10 \mathrm{~mL}$ ice-cold PBS. The cell suspension was centrifuged at $500 \mathrm{~g}$ for $5 \mathrm{~min}$ at $4^{\circ} \mathrm{C}$, and the supernatant was discarded. The cell pellet was diluted in RBC lysis buffer $(5 \mathrm{~mL} / \mathrm{mouse})$ and incubated at room temperature for $10 \mathrm{~min}$, and the supernatant was removed through centrifugation. The cell pellet was suspended in completed Roswell Park Memorial Institute (RPMI) 1640 medium and incubated for $18 \mathrm{~h}$ to be attached to the cell culture plate. To stimulate the cells, the medium was replaced with fresh RPMI 1640 medium, and LPS (200 ng/mL) [18] was added in the presence or absence of HSFE $(10,30$, or $50 \mu \mathrm{g} / \mathrm{mL})$ for the indicated periods. All animal studies were performed according to the Guide for the Animal Care and Use Committee of the Korea Institute of Oriental Medicine (reference numbers \#14-079).

2.11. Chromatographic Conditions. Standardization of HSFE was performed by high-performance liquid chromatography
(HPLC) fingerprinting with chemical standards purchased from Sigma-Aldrich. A standard stock solution containing ampelopsin, taxifolin, and myricetin was dissolved in $1 \mathrm{mg} / \mathrm{mL}$ methanol, and HSFE was weighed accurately and dissolved in $20 \mathrm{mg} / \mathrm{mL}$ methanol for analysis. All samples were filtered through a $0.2 \mu \mathrm{m}$ syringe membrane filter (Whatman Ltd., Maidstone, UK) before injection into the HPLC system for analysis.

The analytical HPLC data were obtained using a Dionex UltiMate 3000 system equipped with a binary pump, autosampler, column oven, and diode array UV/VIS detector. The output signal of the detector was recorded using Chromeleon software for the HPLC system. The analytical HPLC column used in this study was Dionex Acclain ${ }^{\circledR} 120$ $\mathrm{C}_{18}(4.6 \times 150 \mathrm{~mm}, 5 \mu \mathrm{m}$, Dionex Co., CA, USA). HPLC analysis of HSFE was performed in accordance with the methods previously reported by Park et al. [19] with some modifications. In brief, the injection volume of the sample was $10 \mu \mathrm{L}$, and the column temperature was maintained at $40^{\circ} \mathrm{C}$. The mobile phase consisted of water containing (A) $0.1 \%$ TFA and (B) acetonitrile with gradient elution at a flow rate of $0.8 \mathrm{~mL} / \mathrm{min}$. Gradient elution was as follows: $20 \%(v / v) \mathrm{B}$ at $0-3 \mathrm{~min}, 20 \%-30 \% \mathrm{~B}$ at $3-15 \mathrm{~min}$, $30 \%-90 \% \mathrm{~B}$ at $15-18 \mathrm{~min}$, and $90 \% \mathrm{~B}$ at $18-20 \mathrm{~min}$. The identification of the peaks was based on the UV spectrum and retention time of each marker component from the HSFE extract.

2.12. Preparation of the Main Components of HSFE for Cell Application. To confirm the anti-inflammatory activity of the main components of HSFE identified by HPLC analysis in macrophages, each compound was dissolved in $100 \%$ DMSO. The stock concentrations of the three compounds were $20 \mathrm{mM}$ (100\% DMSO), and the intracellular application concentrations were 1,10 , and $50 \mu \mathrm{M}$, respectively (DMSO $0.25 \%$ or less). Using these compounds, the effect on the cell viability in RAW 264.7 macrophages was measured and the inhibitory effect on the secretion of NO and inflammatory cytokine by LPS was confirmed.

2.13. Statistical Analysis. The results are expressed as the mean \pm standard error of the mean (SEM) for all experiments, and all quantitative data are representative of at least three independent experiments. Student's $t$-test was used to determine the statistically significant difference between the control or each treated group and the negative control (LPS). ${ }^{*} P<0.001$ (vs. control) and ${ }^{* *} P<0.001$ (vs. LPS) values were considered as indicating statistical significance.

\section{Results}

3.1. HSFE Treatment Did Not Cause Cytotoxicity in RAW 264.7 Macrophages. The cell viability test of RAW 264.7 macrophages was performed using a CCK after $48 \mathrm{~h}$ of HSFE treatment. The treatment did not affect the cell viability of macrophages at concentrations $>50 \mu \mathrm{g} / \mathrm{mL}$ (Figure 1(a)). Therefore, HSFE was used at a concentration of $\leq 50 \mu \mathrm{g} / \mathrm{mL}$ in the subsequent experiments. 
TABLE 1: Primary and secondary antibodies used for Western blot analysis.

\begin{tabular}{|c|c|c|c|}
\hline Antibody & Corporation & Product no. & Dilution rate \\
\hline iNOS & Cell Signaling Technology & $\# 2977$ & $1: 1,000$ \\
\hline COX-2 & Cell Signaling Technology & $\# 4842$ & $1: 5,000$ \\
\hline$\beta$-Actin & Santa Cruz Biotechnology & \#SC-47778 & $1: 5,000$ \\
\hline P-ERK & Cell Signaling Technology & \#4377 & $1: 1,000$ \\
\hline ERK & Cell Signaling Technology & \#9102 & $1: 1,000$ \\
\hline P-p38 & Cell Signaling Technology & \#9211 & $1: 1,000$ \\
\hline p38 & Cell Signaling Technology & \#9212 & $1: 1,000$ \\
\hline P-JNK & Cell Signaling Technology & \#9251 & $1: 1,000$ \\
\hline JNK & Cell Signaling Technology & \#9252 & $1: 1,000$ \\
\hline P-c-Jun & Cell Signaling Technology & \#9164 & $1: 1,000$ \\
\hline c-Jun & Cell Signaling Technology & \#9165 & $1: 1,000$ \\
\hline TBP & Cell Signaling Technology & \#8515 & $1: 1,000$ \\
\hline P-JAK2 & Santa Cruz Biotechnology & \#SC-21870 & $1: 500$ \\
\hline JAK2 & Santa Cruz Biotechnology & \#SC-294 & $1: 500$ \\
\hline P-STAT1 & Cell Signaling Technology & \#7649 & $1: 1,000$ \\
\hline STAT1 & Cell Signaling Technology & \#9172 & $1: 1,000$ \\
\hline P-STAT3 & Cell Signaling Technology & \#9361 & $1: 1,000$ \\
\hline STAT3 & Cell Signaling Technology & \#9139 & $1: 1,000$ \\
\hline $\mathrm{NF}-\kappa \mathrm{B}$ p 65 & Cell Signaling Technology & \#3034 & $1: 1,000$ \\
\hline $\mathrm{P}-\mathrm{I} \kappa \mathrm{B} \alpha$ & Cell Signaling Technology & \#2859 & $1: 1,000$ \\
\hline $\mathrm{I} \kappa \mathrm{B} \alpha$ & Cell Signaling Technology & \#4814 & $1: 1,000$ \\
\hline Secondary anti-mouse & Cell Signaling Technology & \#7076 & $1: 5,000$ \\
\hline Secondary anti-rabbit & Cell Signaling Technology & \#7074 & $1: 5,000$ \\
\hline
\end{tabular}

TABLE 2: Primers used for real-time RT-PCR.

\begin{tabular}{|c|c|}
\hline $\begin{array}{l}\text { Target } \\
\text { gene }\end{array}$ & Primer sequence \\
\hline \multirow{2}{*}{ TNF- $\alpha$} & $\begin{array}{c}\text { F: } 5^{\prime} \text {-TTCTGTCTACTGAACTTCGGGGTGATCGG } \\
\text { TCC- } 3^{\prime}\end{array}$ \\
\hline & $\begin{array}{c}\text { R: } 5^{\prime} \text {-GTATGAGATAGCAAATCGGCTGACGGTGT } \\
\text { GGG-3' }\end{array}$ \\
\hline \multirow{2}{*}{ IL-6 } & F: $5^{\prime}$-TCCAGTTGCCTTCTTGGGAC-3' \\
\hline & R: 5'-GTGTAATTAAGCCTCCGACTTG-3' \\
\hline \multirow{2}{*}{ IL-1 $\beta$} & F: 5'-ATGGCAACTGTTCCTGAACTCAACT-3' \\
\hline & R: 5'-CAGGACAGGTATAGATTCTTTCCTTT-3' \\
\hline \multirow{2}{*}{ iNOS } & F: 5'-GGCAGCCTGTGAGACCTTTG-3' \\
\hline & R: 5'-GCATTGGAAGTGAAGCGTTTC-3' \\
\hline \multirow{2}{*}{ COX-2 } & F: 5' -TGAGTACCGCAAACGCTTCTC-3' \\
\hline & R: 5' -TGGACGAGGTTTTTCCACCAG-3' \\
\hline \multirow{2}{*}{$\mathrm{HO}-1$} & F: $5^{\prime}$-TGAAGGAGGCCACCAAGGAGG-3' \\
\hline & R: 5'-AGAGGTCACCCAGGTAGCGGG-3' \\
\hline \multirow{2}{*}{$\beta$-Actin } & F: $5^{\prime}$-AGAGGGAAATCGTGCGTGAC-3' \\
\hline & R: 5'-CAATAGTGATGACCTGGCCGT-3' \\
\hline
\end{tabular}

F: forward; R: reverse.
3.2. Inhibitory Effect of HSFE on LPS-Induced NO Secretion and Expression of iNOS and COX-2 in RAW 264.7 Macrophages. We used the Griess assay to investigate whether HSFE treatment regulates NO secretion in LPSstimulated macrophages. Dex, which is widely used as an anti-inflammatory agent, was used as a positive control in all the HSFE pharmacological activity tests, including this experiment. The secretion of NO caused by LPS stimulation was markedly inhibited by HSFE and Dex pretreatment and showed a concentration-dependent inhibitory effect, and at 30 and $50 \mu \mathrm{g} / \mathrm{mL}$ HSFE, the inhibitory activity was superior to that of the positive control drug (Figure 1(b)). We also measured the protein and gene expressions of iNOS and COX-2, the synthetic enzymes of $\mathrm{NO}$ and $\mathrm{PGE}_{2}$, respectively, by Western blot and real-time PCR. iNOS and COX-2 protein expressions were significantly increased by LPS stimulation (Figure 2(a)), and HSFE pretreatment showed strong, dose-dependent inhibition of iNOS, whereas COX-2 was not inhibited at all. In addition, HSFE strongly inhibited iNOS mRNA in a dose-dependent manner with statistical significance, but did not inhibit COX-2 mRNA in any way, showing a pattern similar to the inhibition of protein expression (Figure 2(b)).

3.3. Effects of HSFE on Secretion of TNF- $\alpha$, IL-6, and IL-1 $\beta$ Cytokines and Their mRNA Gene Expressions. Since the expressions of proinflammatory cytokines by specific stimuli sources, such as LPS, are closely related to the elevation of 


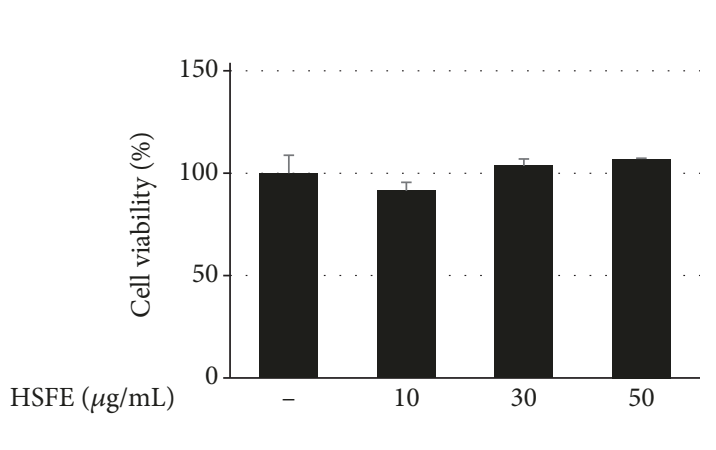

(a)

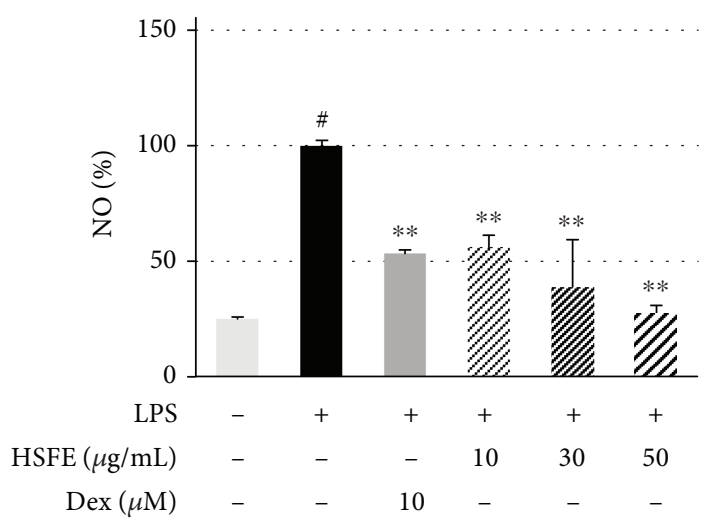

(b)

FIGURE 1: Effects of hoveniae semen seu fructus ethanol (HSFE) extract on (a) cell viability and (b) secretion of NO in macrophages. Cells were seeded with $5.0 \times 10^{4}$ cells/well on a 96-well culture plate and preincubated for $18 \mathrm{~h}$. Then, cells were pretreated with HSFE for $1 \mathrm{~h}$ prior to $24 \mathrm{~h}$ incubation with LPS. At least three independent tests were repeated to ensure reproducibility of the experimental results. (a) Cell viability was examined using a cell-counting kit. (b) NO secretion into the culture media was determined using the Griess assay. As a control, cells were incubated with the vehicle alone. Data represent the mean \pm SEM of duplicate determinations from three independent experiments. ${ }^{\#} P<0.001$ (vs. control) and ${ }^{* *} P<0.001$ (vs. LPS) values were considered statistically significant.

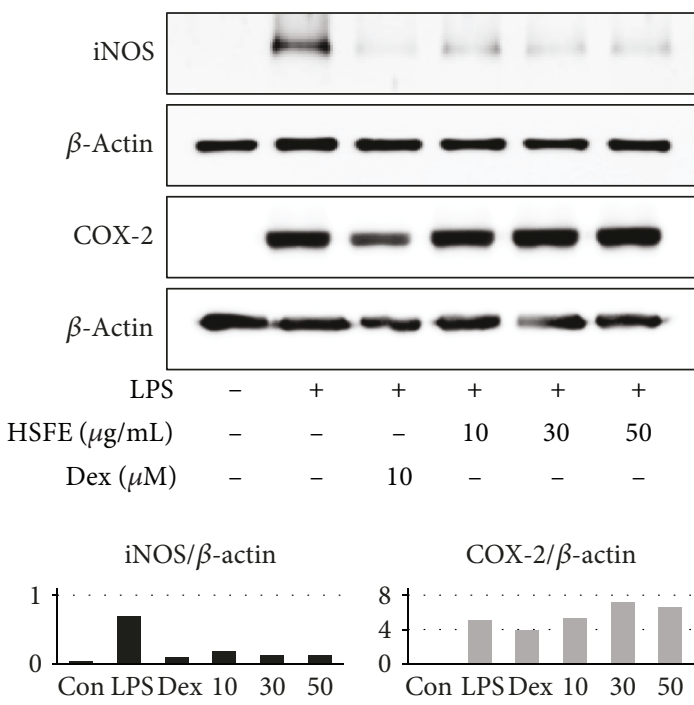

(a)
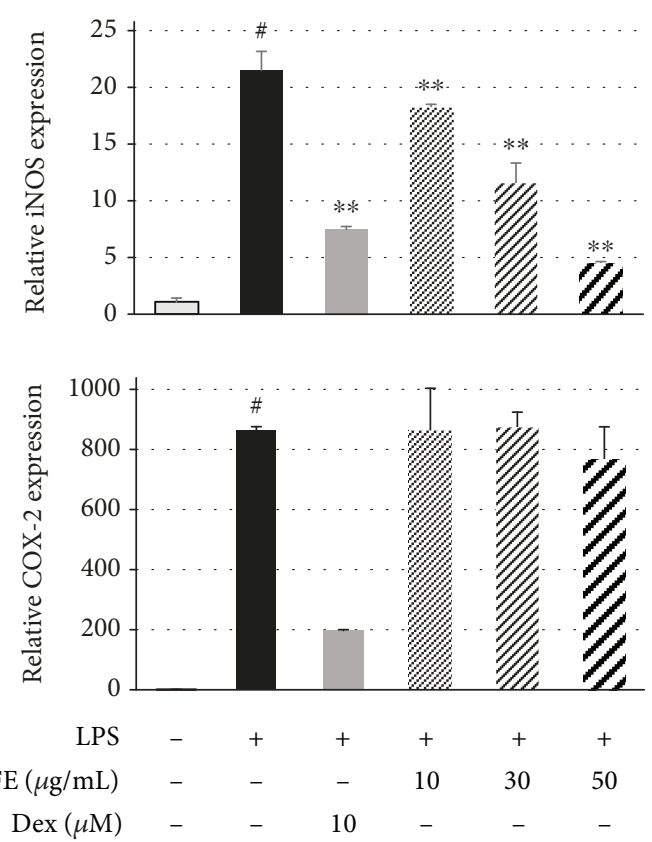

(b)

FIGURE 2: Effects of hoveniae semen seu fructus ethanol (HSFE) extract on (a) iNOS and COX-2 proteins and (b) their mRNA gene expressions. Cells were seeded with $1.5 \times 10^{6}$ cells/well on a 6-well culture plate and preincubated for $18 \mathrm{~h}$. Then, macrophages were stimulated with LPS for $24 \mathrm{~h}$ after $1 \mathrm{~h}$ pretreatment with HSFE. At least three independent tests were repeated to ensure reproducibility. Data in the histograms show protein or mRNA expression levels relative to those of $\beta$-actin. The experiment was repeated three times independently, and similar results were obtained. Data represent the mean \pm SEM from three independent experiments. ${ }^{\#} P<0.001$ (vs. control) and ${ }^{* *} P<0.001$ (vs. LPS) values were considered statistically significant. Con: control.

various acute and chronic inflammatory diseases, we investigated the effect of HSFE on production of different inflammatory cytokines by performing an ELISA and a real-time PCR assay. In Figures 3(a)-3(c), HSFE pretreatment showed little inhibitory effect on TNF- $\alpha$ cytokine production and effectively inhibited the cytokines IL- 6 and IL- $1 \beta$. In parallel, each cytokine mRNA gene exhibited similarly superior and dose-dependent inhibition by HSFE treatment; in particular, TNF- $\alpha$ mRNA exhibited better inhibition than did TNF- $\alpha$ cytokine (Figures 3(d)-3(f)).

3.4. Inhibitory Effect of HSFE Pretreatment on Phosphorylation of the MAPK Protein. MAPK is an important signaling pathway for regulation of the immune response and inflammatory 


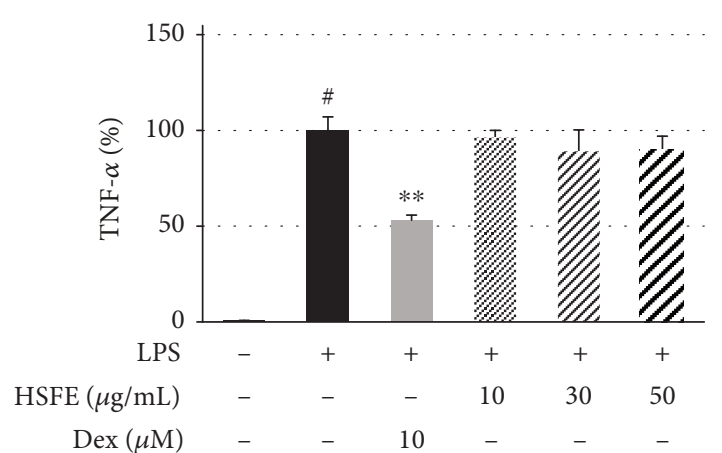

(a)

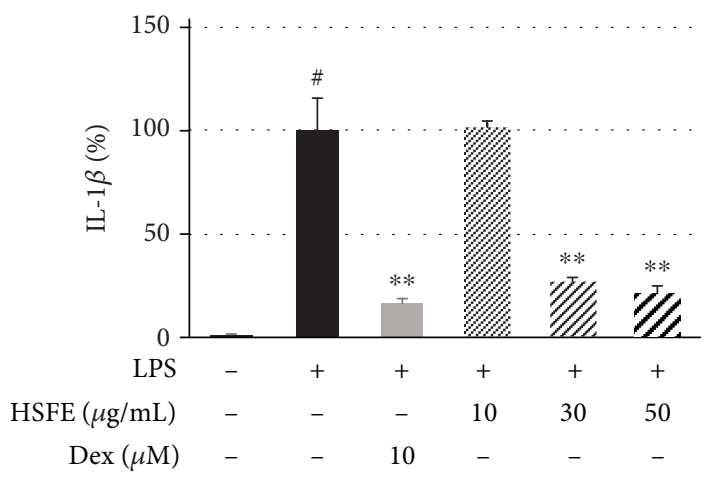

(c)

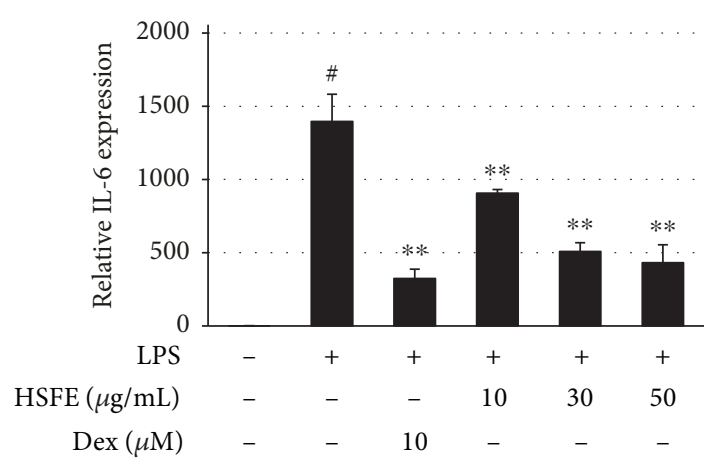

(e)

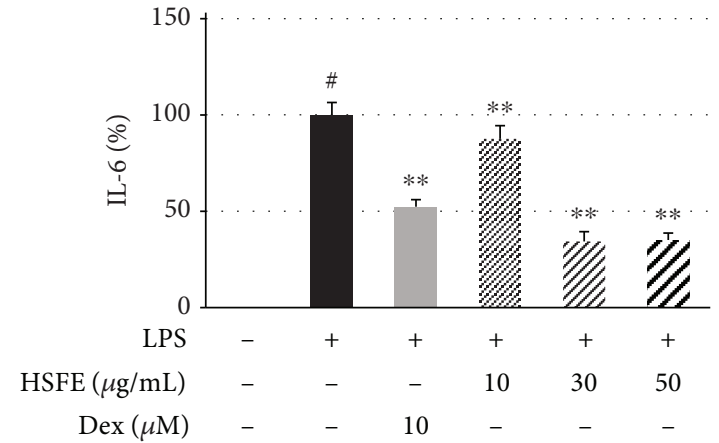

(b)

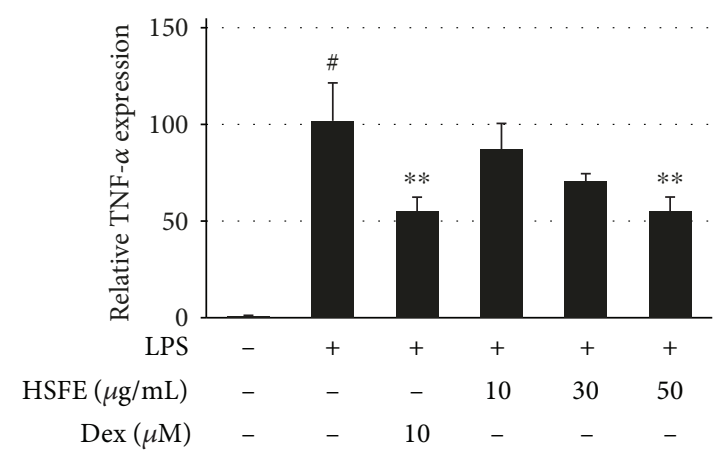

(d)

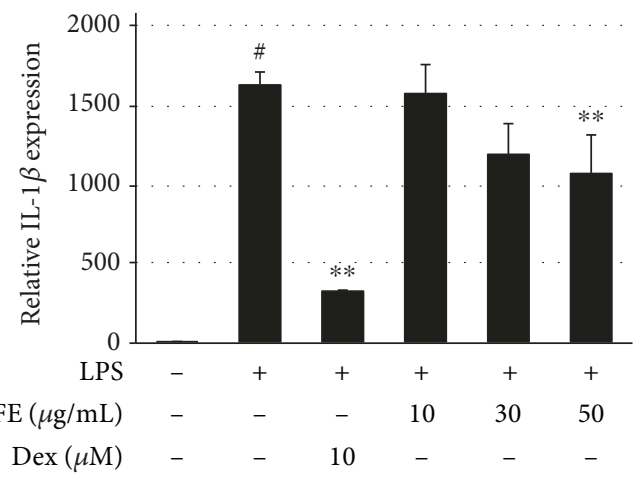

(f)

FIGURE 3: Effects of hoveniae semen seu fructus ethanol (HSFE) extract on $(\mathrm{a}-\mathrm{c}$ ) production of inflammatory cytokines and (d-f) their mRNA expressions after LPS stimulation of macrophages. Cells were seeded with (a-c) $2.5 \times 10^{5}$ cells/well on a 24 -well culture plate or (d-f) $1.5 \times 10^{6}$ cells/well on a 6-well culture plate and preincubated for $18 \mathrm{~h}$. Then, cells were pretreated with HSFE for $1 \mathrm{~h}$ and stimulated with LPS for another $(\mathrm{a}-\mathrm{c}) 24 \mathrm{~h}$ or $(\mathrm{d}-\mathrm{f}) 6 \mathrm{~h}$. At least three independent tests were repeated to ensure reproducibility. Data represent the mean \pm SEM of duplicate determinations from three independent experiments. ${ }^{\#} P<0.001$ (vs. control) and ${ }^{* *} P<0.001$ (vs. LPS) values were considered statistically significant.

factor expression and has an important role in regulating NF- $\kappa \mathrm{B}$ activation, and phosphorylation of MAPK is closely related to modulation of AP-1 activation. We therefore investigated the effect by pretreatment of HSFE on activation of the MAPK proteins ERK, p38, and JNK on LPS stimulation. Western blot analysis indicated that HSFE showed dramatic and dose-dependent attenuation of phosphorylation of three proteins at concentrations $>30 \mu \mathrm{g} / \mathrm{mL}$ and did not affect the amount of each total-form protein (Figure 4).

3.5. HSFE Pretreatment Has an Inhibitory Effect on LPSInduced AP-1 Signaling Pathway Activation. AP-1 is another important transcription factor and is linked to the production of several proinflammatory mediators [9]. AP-1 migrates into the nucleus and regulates expression of certain inflammatory genes when macrophages become inflammatory in response to conditions caused by stimuli, such as LPS. We therefore measured the level of phosphorylation in the cytoplasm and the amount transferred into the nucleus of the AP-1 subunit c-Jun protein. Figure 5(a) shows LPS stimulation-related phosphorylation and migration into the nucleus of the c-Jun protein, whereas HSFE pretreatment effectively and strongly inhibited nuclear transfer and phosphorylation of c-Jun. 

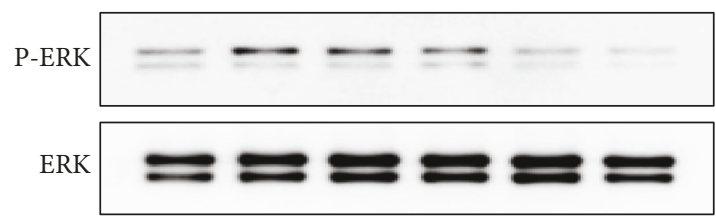

(a)

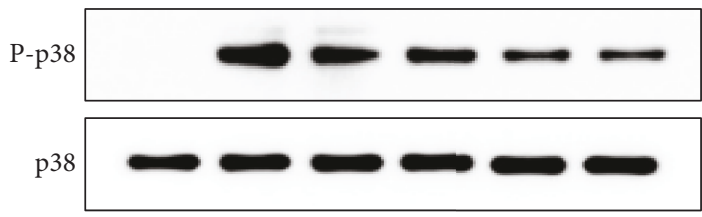

(b)

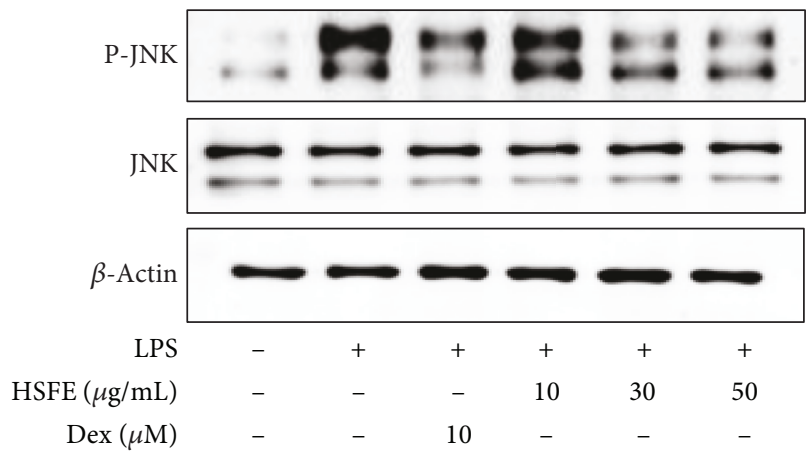

(c)
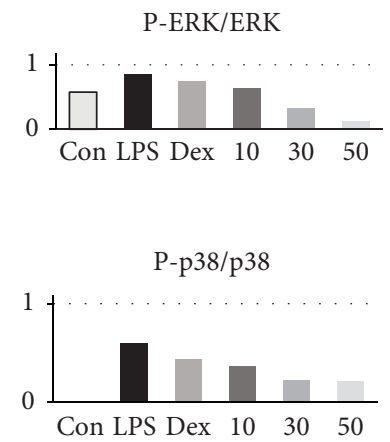

P-JNK/JNK

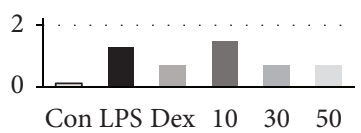

FIgURE 4: Effects of hoveniae semen seu fructus ethanol (HSFE) extract on phosphorylation of (a) ERK, (b) p38, and (c) JNK mitogenactivated protein kinases in macrophages. Cells were seeded with $1.5 \times 10^{6}$ cells/well on a 6 -well culture plate and preincubated for $18 \mathrm{~h}$. Then, cells were treated with HSFE for $1 \mathrm{~h}$ and stimulated with LPS for another $30 \mathrm{~min}$. At least three independent tests were repeated to ensure reproducibility. Total ERK, p38, and JNK served as the controls for their phosphorylated forms. Data in the histograms show protein expression levels relative to those of total-type protein. The results shown are representative of three separate experiments. Con: control.

3.6. Effect of HSFE on Activation of the JAK/STAT Signaling Pathway in LPS-Stimulated RAW 264.7 Cells. Several previous studies have reported that mitigation of the JAK/STAT signaling pathway inhibited LPS-induced NO and proinflammatory cytokine production [20]. Therefore, we measured the HSFE effect on phosphorylation of JAK2, STAT1, and STAT3 in RAW 264.7 cells stimulated with LPS by Western blot. As shown in Figure 5(b), HSFE treatment significantly blocked phosphorylation of JAK2, STAT1, and STAT3 at concentrations of $30-50 \mu \mathrm{g} / \mathrm{mL}$ and did not affect the total protein level. These results indicate that HSFE treatment not only inhibited phosphorylation and nuclear transcription of the c-Jun protein but also inhibited JAK/STAT pathway activation.

\subsection{Effect of HSFE on p65 Translocation in LPS-Stimulated} $R A W$ 264.7 Cells. The transcription factor NF- $\kappa \mathrm{B}$ is a pivotal regulator closely associated with inflammatory responses. Thus, we examined whether HSFE inhibits LPS-induced p65 translocation and inhibition of NF- $\kappa \mathrm{B}$ alpha $(\mathrm{I} \kappa \mathrm{B} \alpha)$ phosphorylation. Our data show that HSFE exclusively blocks p65 translocation in the nucleus in a concentrationdependent manner (Figures 6(a) and 6(b)). Additionally, as seen in the Western blot analysis, HSFE inhibits degradation and activation of $\mathrm{I} \kappa \mathrm{B} \alpha$ by LPS stimulation (Figure $6(\mathrm{c})$ ) in a concentration-dependent manner. These results suggest that HSFE reduces the translocation of the NF- $\kappa \mathrm{B}$ subunit $\mathrm{p} 65$ by preventing the $\mathrm{I} \kappa \mathrm{B} \alpha$ degradation.

3.8. Effect of HSFE on LPS-Induced Cytokine Levels in Mouse Peritoneal Macrophages. To confirm the anti-inflammatory efficacy of HSFE in mouse primary macrophages, we also measured inflammatory cytokine levels in LPS-stimulated mouse peritoneal macrophages via ELISA. HSFE pretreatment did not affect the cell viability of the primary macrophages (Figure 7(a)) and strongly inhibited TNF- $\alpha$, IL-6, IL-1 $\beta$, and interferon- (IFN-) $\gamma$ cytokine secretion in a dose-dependent manner (Figures 7(b)-7(e)); additionally, each cytokine secretion was inhibited by $93 \%, 91 \%, 63 \%$, and $95 \%$, respectively, at the $50 \mu \mathrm{g} / \mathrm{mL}$ concentration of HSFE treatment.

3.9. HPLC Analysis of HSFE. The constituents of HSFE were determined by HPLC analysis, and each peak of UV spectra was compared with that of representative standard compounds. As described in Figure 8(a), at the $280 \mathrm{~nm}$ UV detection wavelength, the retention times of ampelopsin, taxifolin, and myricetin in the standard mixture were $4.93,8.14$, and $11.30 \mathrm{~min}$, respectively. Under the same conditions, the retention times of the observed components were 4.93, 8.07, and $11.26 \mathrm{~min}$ in HSFE, respectively (Figure 8(b)). 

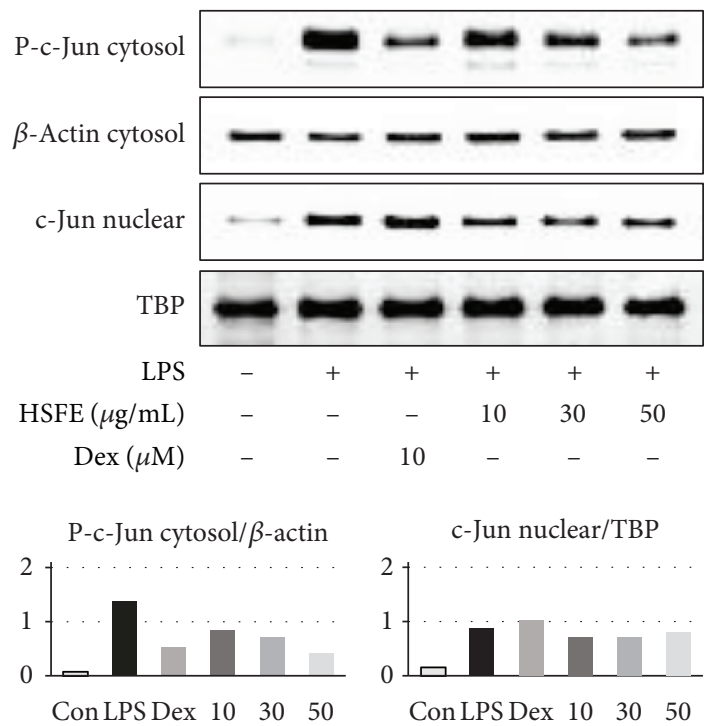

(a)
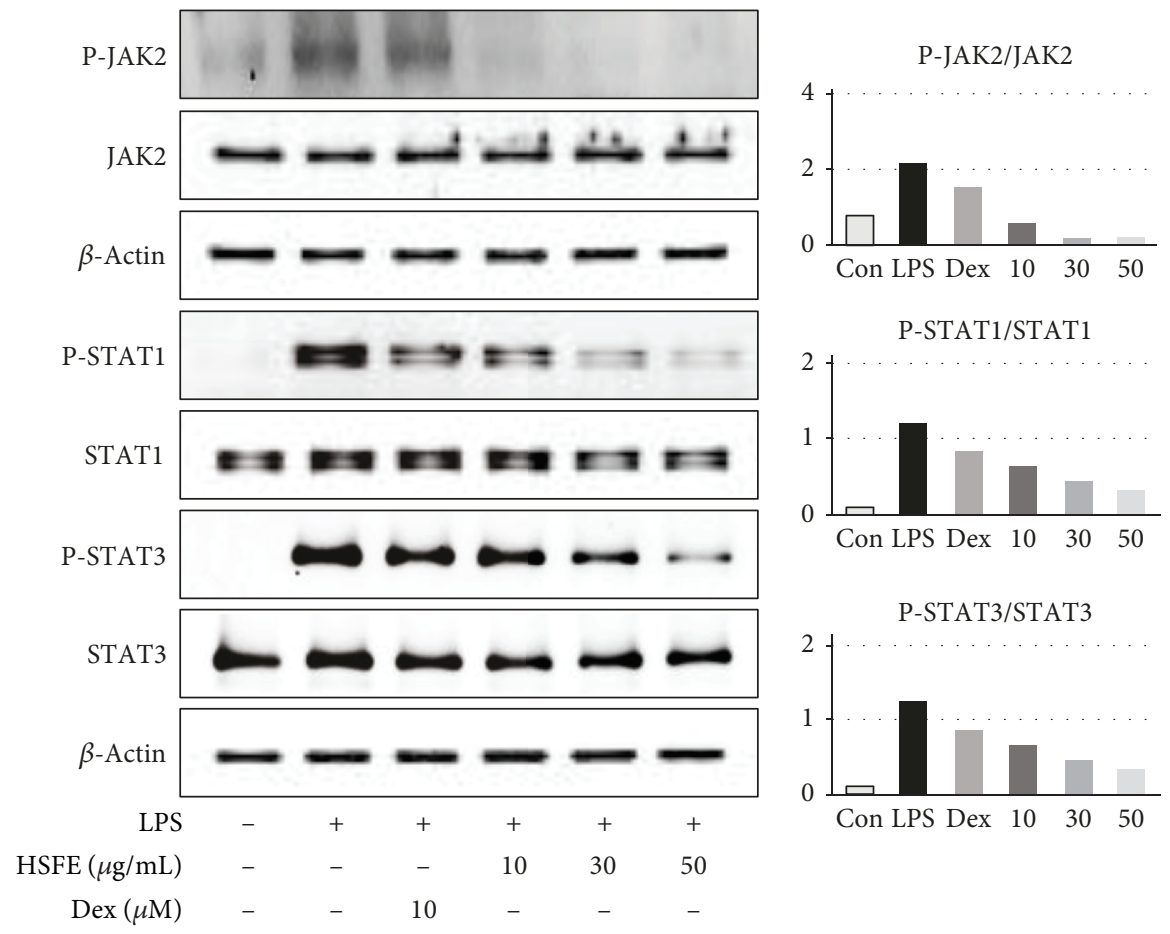

(b)

Figure 5: Effects of hoveniae semen seu fructus ethanol (HSFE) extract on (a) phosphorylation and nuclear translocation of c-Jun and (b) phosphorylation of JAK2/STAT1-3. Cells were seeded with $1.5 \times 10^{6}$ cells/well on a 6-well culture plate and preincubated for $18 \mathrm{~h}$. Then, cells were pretreated with HSFE for $1 \mathrm{~h}$ and stimulated with LPS for another (a) $30 \mathrm{~min}$ or (b) $4 \mathrm{~h}$. At least three independent tests were repeated to ensure reproducibility. $\beta$-Actin and TATA box-binding protein (TBP) served as the controls for cytosolic and nuclear proteins, respectively. Data in the histograms show protein expression levels relative to $\beta$-actin or TBP. The results shown are representative of three separate experiments. Con: control.

3.10. Verification of Anti-Inflammatory Efficacy of Ampelopsin, Taxifolin, and Myricetin in LPS-Stimulated RAW 264.7 Macrophages. The following experiments were carried out to confirm the inhibitory effects of the three major components of HSFE on macrophage inflammatory responses. First, the influence of the three compounds on the viability of macrophages was measured using a CCK. Ampelopsin and taxifolin showed no toxicity to macrophages at $1-50 \mu \mathrm{M}$, whereas myricetin showed weak cytotoxicity at $50 \mu \mathrm{M}$ (survival of $90 \%$ or more) but did not affect the subsequent test (Figure 9(a)). Next, the effects of the three compounds on $\mathrm{NO}$ and inflammatory cytokine release in LPS-induced inflammatory responses were analyzed. Ampelopsin, taxifolin, and myricetin suppressed the secretion of NO in a 


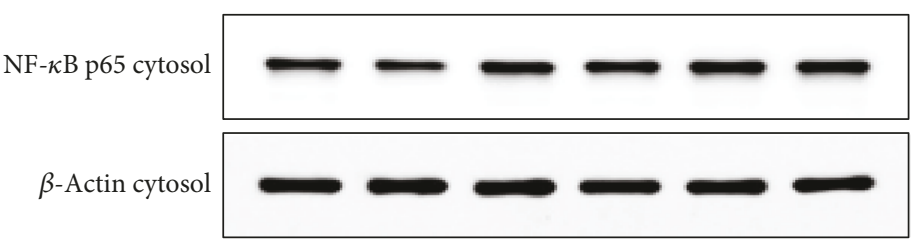

(a)
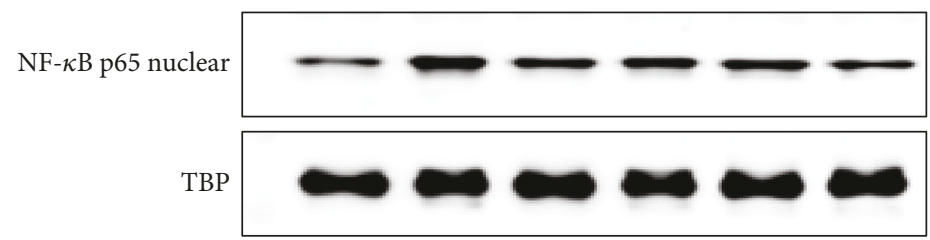

(b)

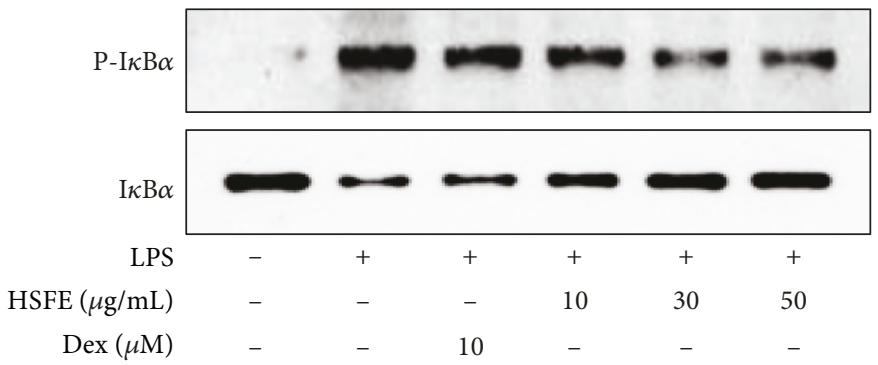

(c)
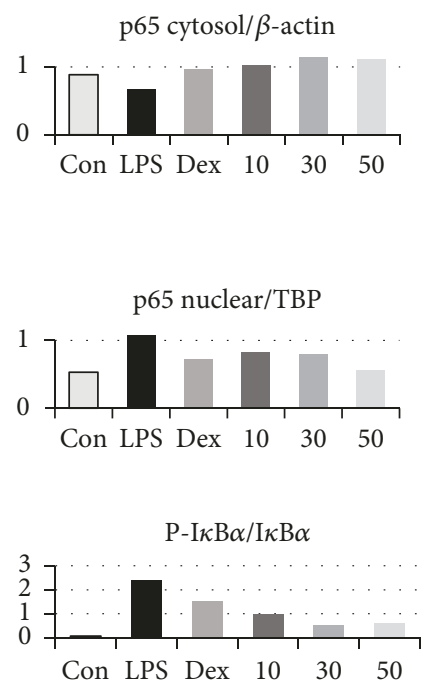

Figure 6: Effects of hoveniae semen seu fructus ethanol (HSFE) extract on ( $a, b)$ nuclear translocation of NF- $\kappa$ B p65 and (c) degradation of $\mathrm{I} \kappa \mathrm{B} \alpha$. Cells were seeded with $1.5 \times 10^{6}$ cells/well on a 6-well culture plate and preincubated for $18 \mathrm{~h}$. Then, cells were pretreated with HSFE for $1 \mathrm{~h}$ and stimulated with LPS for another $(\mathrm{a}, \mathrm{b}) 1 \mathrm{~h}$ or (c) $30 \mathrm{~min}$. At least three independent tests were repeated to ensure reproducibility. $\beta$-Actin and TBP served as the controls for cytosolic and nuclear proteins, respectively. Data in the histograms show protein expression levels relative to those of $\beta$-actin, TBP, or $\mathrm{I} \kappa \mathrm{B} \alpha$. The results shown are representative of three separate experiments. Con: control.

concentration-dependent manner and showed a statistically significant inhibitory activity when each compound was pretreated at a high concentration $(50 \mu \mathrm{M})($ Figure $9(\mathrm{~b}))$. Only taxifolin showed a weak inhibitory activity against the inflammatory cytokine TNF- $\alpha$ at high concentration $(50 \mu \mathrm{M})$ (Figure 9(c)), and IL-6 secretion was relatively effectively repressed by all compounds in a concentration-dependent manner and was statistically significant (Figure 9(d)). IL-1 $\beta$ cytokine secretion was most effectively inhibited by pretreatment of the three compounds, with significant inhibition at all concentrations and increased efficacy in a concentrationdependent manner (Figure 9(e)).

\section{Discussion}

In previous studies, HSF has been reported to exhibit antiinflammatory efficacy through blockade of the NF- $\kappa$ B pathway in inflammatory macrophages. However, as potential therapeutic candidates, the effects of HSF on a variety of other signaling pathways involved in intracellular inflammatory responses and the scientific evidence remain unexplored. We therefore investigated the anti-inflammatory efficacy and other potential inhibitory mechanisms of HSFE in inflammatory-conditioned macrophages. In addition, the HSFE anti-inflammatory activity was confirmed in LPSstimulated mouse primary macrophages. We first evaluated the effect of HSFE at $\leq 50 \mu \mathrm{g} / \mathrm{mL}$ on the viability of macrophages and found that they did not show cytotoxicity, and subsequent experiments were performed at three concentrations. Next, the inhibitory activity of HSFE against NO production, the most basic parameter for evaluation of antiinflammatory activity, was confirmed, and the effects on iNOS and COX-2 expressions were examined. iNOS and COX-2 are enzymes that synthesize $\mathrm{NO}$ and $\mathrm{PGE}_{2}$ from $\mathrm{L}$-arginine and arachidonic acid, respectively, and are important targets in the study of anti-inflammatory agents $[21,22]$. HSFE treatment had a superior inhibitory effect on iNOS expression, which demonstrated that the inhibitory effect on NO production was related to iNOS inhibition, but HSFE had no inhibitory effect on COX-2 expression. We also explored the efficacy of HSFE on secretion and mRNA gene expression of the proinflammatory cytokines, TNF- $\alpha$, IL-6, and IL- $1 \beta$, and proved that HSFE treatment exerted strong inhibitory activity against IL- 6 and IL- $1 \beta$ production except against TNF- $\alpha$.

To explore additional mechanisms of the HSFE antiinflammatory activity, we investigated the effects of HSFE on activation of the MAPK, AP-1, and JAK/STAT signaling pathways by LPS stimulation. In macrophages, MAPK and AP-1 are important regulators of various genes of encoded inflammatory factors [23], MAPK has a vital role in signal transduction pathways in controlling immune responses and inflammatory factors [24], and MAPK phosphorylation after LPS stimulation is known to regulate AP-1 activation $[7,25]$. AP-1 is an essential transcription factor consisting of the c-Jun/c-Fos heterodimer and is present in the 


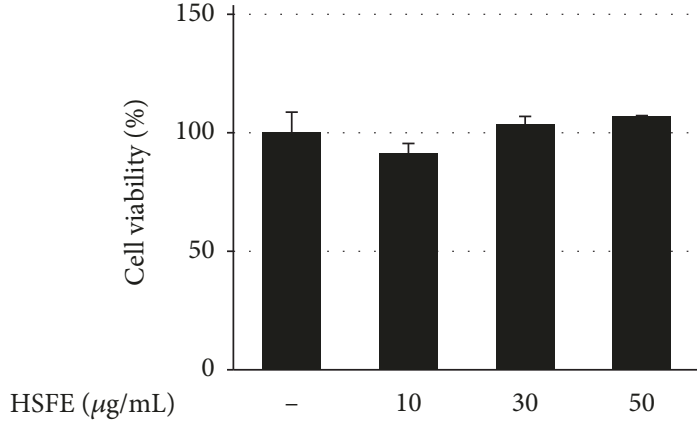

(a)

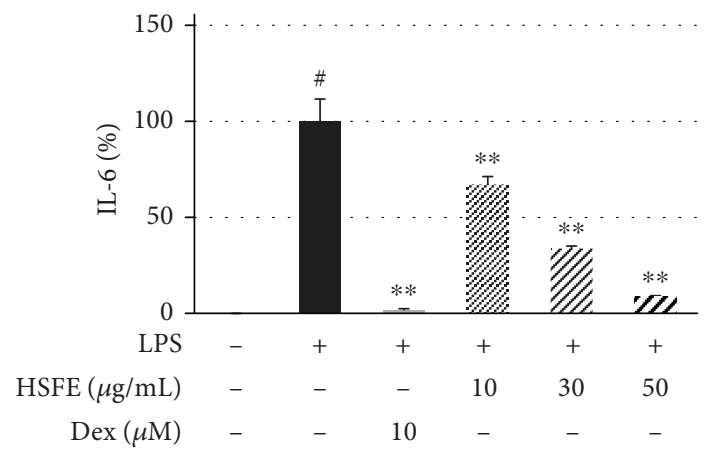

(c)

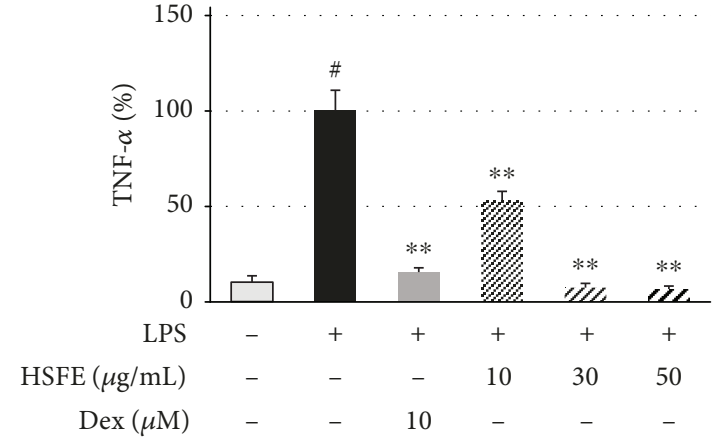

(b)

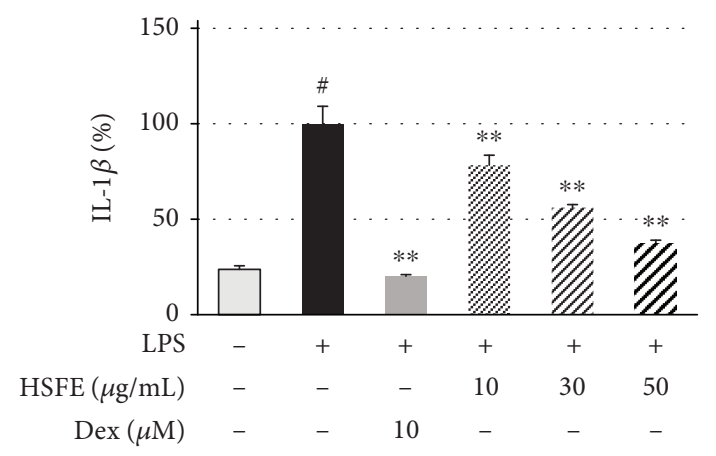

(d)

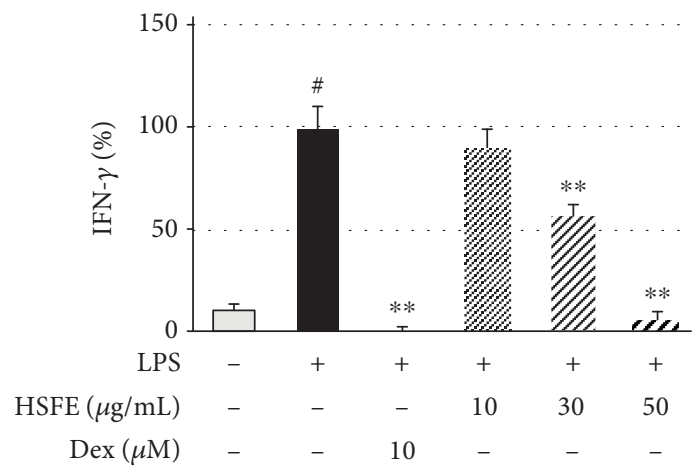

(e)

FIGURE 7: Effects of hoveniae semen seu fructus ethanol (HSFE) extract on (a) cell viability and production of the inflammatory cytokines (b) TNF- $\alpha$, (c) IL-6, (d) IL- $1 \beta$, and (e) IFN- $\gamma$ in mouse peritoneal macrophages. The primary macrophages obtained from 6 BALB/c mice were seeded with (a) $5.0 \times 10^{4}$ cells/well on a 96-well culture plate or (b-e) $2.5 \times 10^{5}$ cells/well on a 24 -well culture plate and preincubated for $18 \mathrm{~h}$. Then, cells were pretreated with HSFE for $1 \mathrm{~h}$ and then stimulated with LPS for another $24 \mathrm{~h}$. At least three independent tests were repeated to ensure reproducibility of the experimental results. As a control, cells were incubated with vehicle alone. Data represent the mean \pm SEM of duplicate determinations from three independent experiments. ${ }^{\#} P<0.001$ (vs. control) and ${ }^{* *} P<0.001$ (vs. LPS) values were considered statistically significant.

cytoplasm as a quiescent form in unstimulated cells [26]. By inflammatory stimulation, AP-1 is activated and migrates into the nucleus, which promotes the production of proinflammatory mediators $[27,28]$. Therefore, we first assessed the efficacy of HSFE on activation of the MAPK proteins ERK, p38, and JNK by LPS stimulation, which demonstrated that HSFE pretreatment effectively inhibited phosphorylation of each MAPK protein. In addition, we examined the effect of HSFE on intracellular phosphorylation levels and nuclear transfer of c-Jun protein by LPS treatment to mea- sure the effect on AP-1 activation and demonstrated that HSFE treatment strongly inhibited both phosphorylation and nuclear translocation of AP-1. These results indicated that the anti-inflammatory activity of HSFE was due not only to blockade of the NF- $\kappa \mathrm{B}$ pathway known in previous studies but also to inhibition of activation of the MAPK and AP-1 pathways.

As an inflammatory pathway, the JAK/STAT pathway is known to elicit production of multiple inflammatory factors through phosphorylation and is recognized as having a 


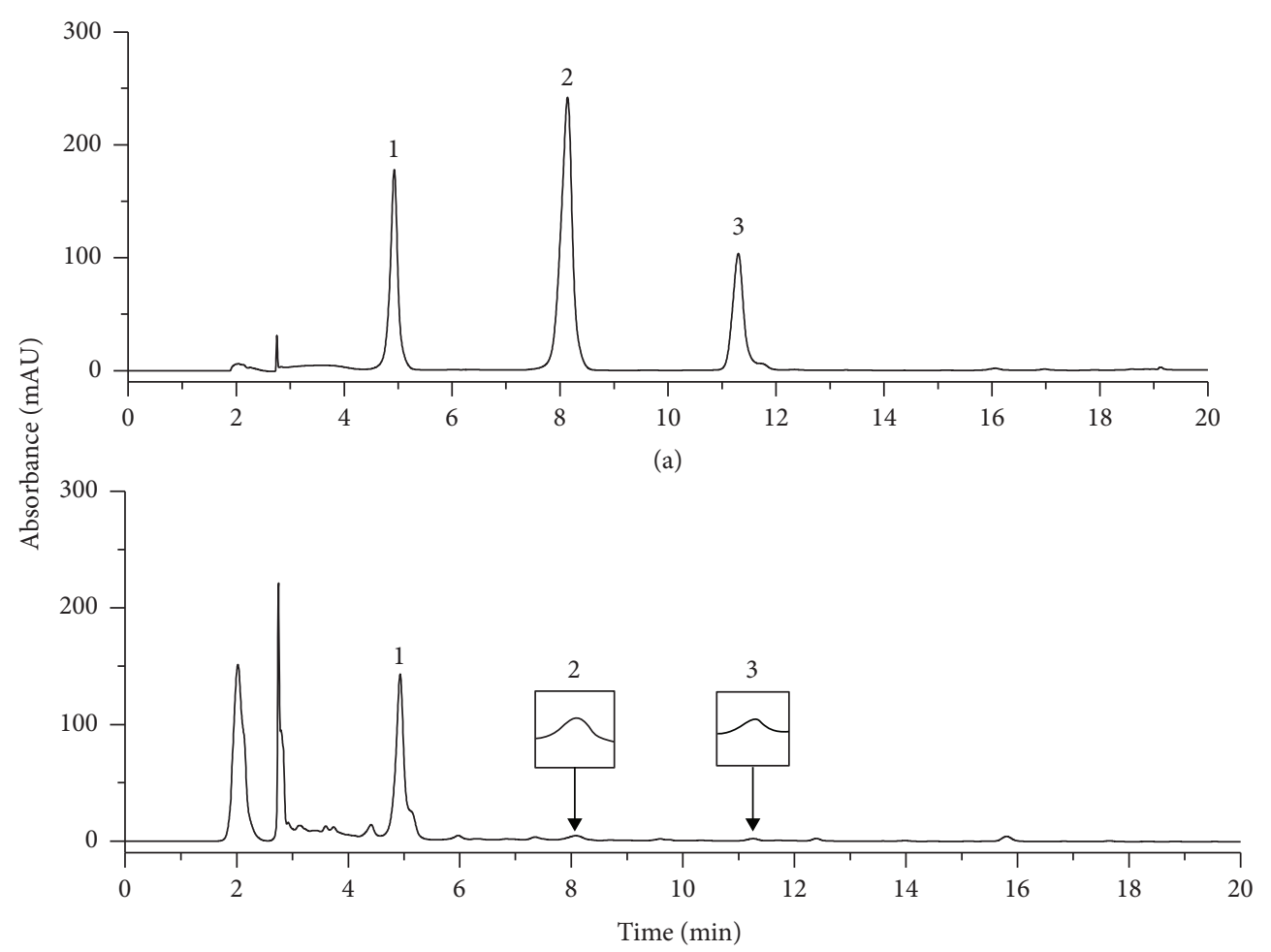<smiles>O=C1c2c(O)cc(O)cc2OC(c2cc(O)c(O)c(O)c2)C1O</smiles><smiles>O=C1c2c(O)cc(O)cc2O[C@H](c2cc(O)c(O)c(O)c2)[C@@H]1O</smiles>

2: taxifolin<smiles>O=c1c(O)c(-c2cc(O)c(O)c(O)c2)oc2cc(O)cc(O)c12</smiles>

(b)

FIGURE 8: HPLC chromatograms of (a) three standard mixtures and (b) HSFE at $280 \mathrm{~nm}$. 1: ampelopsin; 2: taxifolin; 3: myricetin. (a) Standard compound: $280 \mathrm{~nm}$, (b) HSFE: $280 \mathrm{~nm}$.

central role in the immune and inflammatory responses $[9,29]$. The JAK/STAT signaling pathway is activated by stimuli, such as LPS, to induce phosphorylation of downstream molecules, such as STAT1, which results in the translocation into the nucleus and binding to promoter regions of various proinflammatory mediators [30]. In addition, the activation of STAT3 has a direct effect on the IL-6 cytokine secretion [31]. Therefore, we measured whether the anti-inflammatory effect of HSFE in macrophages is associated with the inhibition of phosphorylation of the JAK2/STAT1-3 proteins, and as a result, HSFE treatment effectively inhibited phosphorylation of JAK2, STAT1, and STAT3. These results showed that HSFE treatment exerted anti-inflammatory activity by controlling the inflammatory response through inhibition of JAK/STAT activity in macrophages. In the case of natural products, the efficacy may vary depending on conditions, such as cultivated land and climate, so we have reexamined the inhibitory effect of HSFE on $\mathrm{NF}-\kappa \mathrm{B}$ activation, which has been studied previously, and confirmed its robust activity.

Finally, we confirmed the anti-inflammatory activity of HSFE in LPS-stimulated mouse primary macrophages. As in the cell line, HSFE treatment did not show cytotoxicity at concentrations of $<50 \mu \mathrm{g} / \mathrm{mL}$ and effectively inhibited production of TNF- $\alpha$, IL- 6 , IL- $1 \beta$, and IFN- $\gamma$ cytokines at all three concentrations. One peculiarity is that, unlike in RAW 264.7 cell lines, HSFE pretreatment in the LPS-stimulated mouse primary macrophages had a potent and dose-dependent inhibitory effect on secretion of TNF- $\alpha$.

As shown in Figure 8, we identified three main components of HSFE (ampelopsin, taxifolin, and myricetin) consistent with previous studies [19]. Previous studies have shown that ampelopsin attenuates the inflammatory response by inhibiting NF- $\kappa \mathrm{B}$ and JAK/STAT signaling pathways in LPS-stimulated BV2 microglia [32] and suppresses inflammation by blocking the activation of PI3K/Akt/NF- $\kappa \mathrm{B}$ in RAW 264.7 macrophages [33]. In another study, taxifolin repressed NF- $\kappa \mathrm{B}$ via upregulation of the nuclear factor erythroid 2-related factor $2(\mathrm{Nrf}-2)$ pathway in experimental colon carcinogenesis [34], and myricetin inhibited the early inflammatory response by LPS [35]. In addition, recent studies have shown that myricetin inhibits Akt, mTOR, and $\mathrm{NF}-\kappa \mathrm{B}$ in human keratinocytes, thereby reducing the expression of inflammatory factors [36], and exhibits antiinflammatory activity through inhibition of NF- $\kappa \mathrm{B}$, STAT1 activation, and HO-1 induction in RAW 264.7 macrophages [37]. These previous results indicate that the antiinflammatory effect of HSFE is closely related to the activities of the three components (ampelopsin, taxifolin, and myricetin). In connection with the above, to confirm the antiinflammatory activity of the main components of HSFE, we measured the inhibitory activities of ampelopsin, taxifolin, and myricetin on LPS-induced secretion of NO and inflammatory cytokines, including TNF- $\alpha$, IL-6, and IL- $1 \beta$, in RAW 264.7 macrophages. As a result, all three compounds 


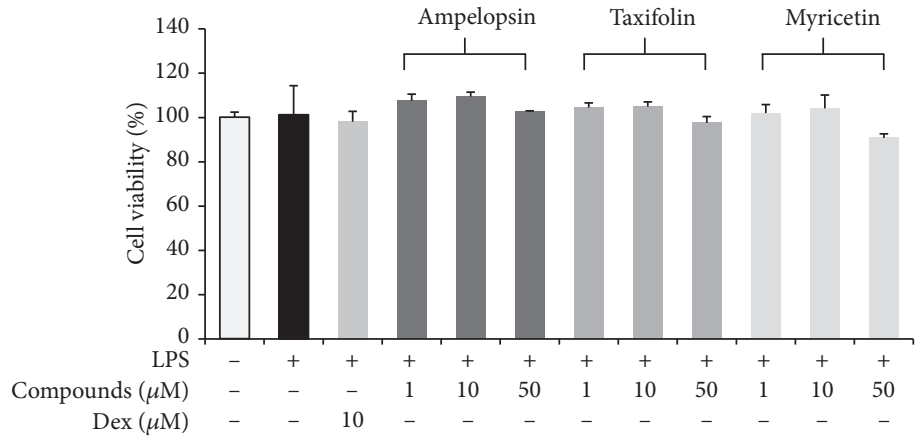

(a)

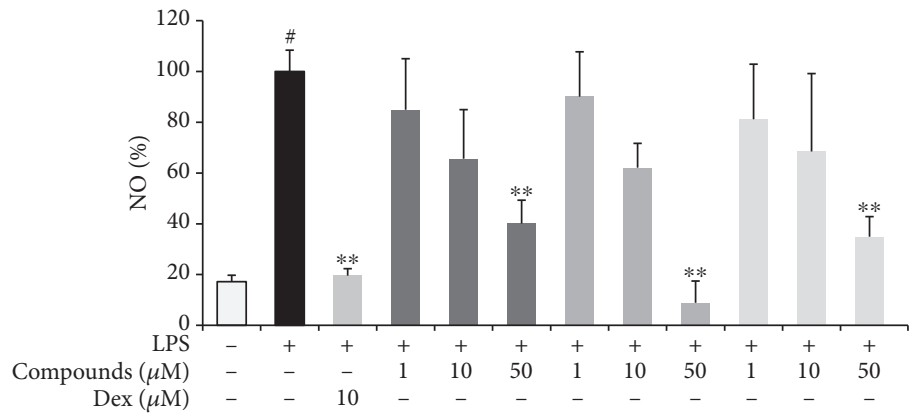

(b)

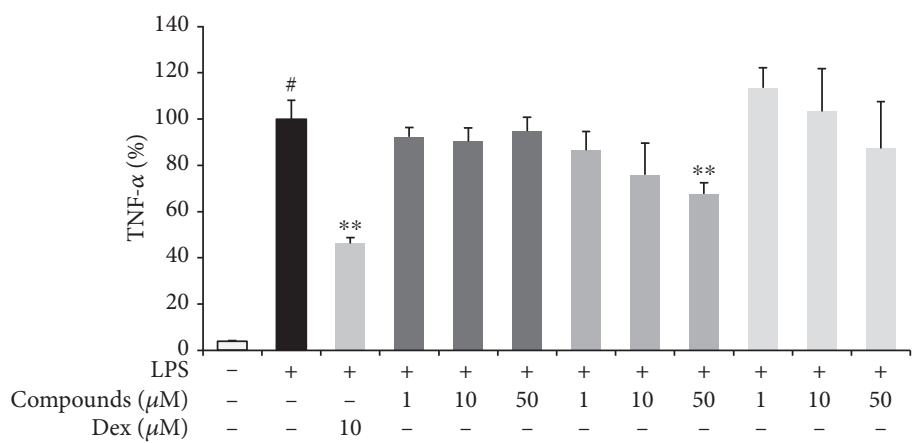

(c)

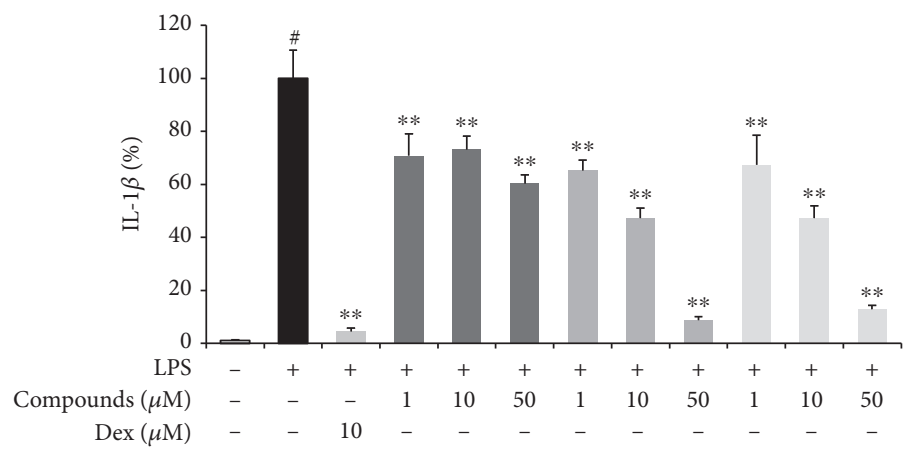

(d)

FIGURE 9: Effects of three compounds, ampelopsin, taxifolin, and myricetin, on (a) cell viability and the secretion of (b) NO and (c-e) inflammatory cytokines. Cells were seeded with $(\mathrm{a}, \mathrm{b}) 5.0 \times 10^{4}$ cells/well on a 96-well culture plate or $(\mathrm{c}-\mathrm{e}) 2.5 \times 10^{5}$ cells/well on a 24-well culture plate and preincubated for $18 \mathrm{~h}$. Then, cells were pretreated with each compound for $1 \mathrm{~h}$ and stimulated with LPS for another $24 \mathrm{~h}$. At least three independent tests were repeated to ensure reproducibility of the experimental results. (a) Cell viability was examined using a cell-counting kit. (b) NO secretion into the culture media was determined using the Griess assay. (c-e) Secretion of inflammatory cytokines was measured by ELISA. As a control, cells were incubated with vehicle alone. Data represent the mean \pm SEM of duplicate determinations from three independent experiments. ${ }^{\#} P<0.001$ (vs. control) and ${ }^{* *} P<0.001$ (vs. LPS) values were considered statistically significant. 
showed effective anti-inflammatory activity in a concentration range that is not toxic to macrophages.

Considering the results of this study, HSFE has excellent control over inflammatory reactions at the in vitro level. HSFE has been used in the treatment of indirectly related diseases, although it is not a specialized herbal drug for inflammatory diseases in traditional medicine in East Asia, and the findings of this study suggest scientific evidence for this traditional theory. Based on the results, HSFE can be considered as a potential candidate for the prevention or treatment of inflammatory diseases in clinical applications after further in vivo study.

In summary, our study demonstrated that HSFE treatment suppressed the release of NO, iNOS, and inflammatory cytokines in RAW 264.7 macrophages stimulated by LPS and its efficacy was due to the inhibition of MAPK phosphorylation and blocking of AP-1, JAK2/STAT, and NF- $\kappa$ B activation. In addition, our study showed that HSFE inhibited secretion of TNF- $\alpha$, IL- 6 , IL- $1 \beta$, and IFN- $\gamma$ cytokines in mouse primary macrophages. Also, the anti-inflammatory efficacy of HSFE seems to be closely related to the presence of three main components (ampelopsin, taxifolin, and myricetin). These findings provide a novel insight into the antiinflammatory activity of HSFE and its molecular mechanism of action.

\section{Data Availability}

The data used to support the findings are available from the corresponding author upon request.

\section{Conflicts of Interest}

The authors declare that there are no conflicts of interest.

\section{Authors' Contributions}

JYM developed the study design and critically revised the manuscript. YHJ and YCO participated in the study design, carried out the experiments, analyzed the data, and wrote the draft manuscript. WKC participated in the study design, carried out the experiments, and analyzed the data. NHY conducted HPLC analysis. All authors read and approved the final manuscript. YHJ and YCO contributed equally to this work (co-first authors).

\section{Acknowledgments}

This work was supported by the grants K17281 and K18101 awarded to Korea Institute of Oriental Medicine (KIOM) from the Ministry of Science and ICT, Republic of Korea.

\section{References}

[1] L. M. Coussens and Z. Werb, "Inflammation and cancer," Nature, vol. 420, no. 6917, pp. 860-867, 2002.

[2] M. Philip, D. A. Rowley, and H. Schreiber, "Inflammation as a tumor promoter in cancer induction," Seminars in Cancer Biology, vol. 14, no. 6, pp. 433-439, 2004.
[3] D. J. Wadleigh, S. T. Reddy, E. Kopp, S. Ghosh, and H. R. Herschman, "Transcriptional activation of the cyclooxygenase-2 gene in endotoxin-treated RAW 264.7 macrophages," Journal of Biological Chemistry, vol. 275, no. 9, pp. 6259-6266, 2000.

[4] C. Y. Lin, C. H. Lee, Y. W. Chang, H. M. Wang, C. Y. Chen, and Y. H. Chen, "Pheophytin a inhibits inflammation via suppression of LPS-induced nitric oxide synthase-2, prostaglandin $\mathrm{E}_{2}$, and interleukin- $1 \beta$ of macrophages," International Journal of Molecular Sciences, vol. 15, no. 12, pp. 22819-22834, 2014.

[5] B. C.-Y. Cheng, X. Q. Ma, H. Y. Kwan et al., "A herbal formula consisting of Rosae Multiflorae Fructus and Lonicerae Japonicae Flos inhibits inflammatory mediators in LPSstimulated RAW 264.7 macrophages," Journal of Ethnopharmacology, vol. 153, no. 3, pp. 922-927, 2014.

[6] J. M. Kyriakis and J. Avruch, "Mammalian MAPK signal transduction pathways activated by stress and inflammation: a 10-year update," Physiological Reviews, vol. 92, no. 2, pp. 689-737, 2012.

[7] J. Chun, R. J. Choi, S. Khan et al., “Alantolactone suppresses inducible nitric oxide synthase and cyclooxygenase-2 expression by down-regulating NF- $\kappa \mathrm{B}, \mathrm{MAPK}$ and AP- 1 via the MyD88 signaling pathway in LPS-activated RAW 264.7 cells," International Immunopharmacology, vol. 14, no. 4, pp. 375383, 2012.

[8] R. Wisdom, “AP-1: one switch for many signals," Experimental Cell Research, vol. 253, no. 1, pp. 180-185, 1999.

[9] P. J. Murray, “The JAK-STAT signaling pathway: input and output integration," Journal of Immunology, vol. 178, no. 5, pp. 2623-2629, 2007.

[10] S. Chen, G. Zhong, A. Li, S. H. Li, and L. K. Wu, "Influence of Hovenia dulcis on alcohol concentration in blood and activity of alcohol dehydrogenase (ADH) of animals after drinking," Zhongguo Zhong Yao Za Zhi, vol. 31, no. 13, pp. 1094-1096, 2006.

[11] T. K. Hyun, S. H. Eom, C. Y. Yu, and T. Roitsch, "Hovenia dulcis-an Asian traditional herb," Planta Medica, vol. 76, no. 10, pp. 943-949, 2010.

[12] M. Wang, P. Zhu, C. Jiang, L. Ma, Z. Zhang, and X. Zeng, "Preliminary characterization, antioxidant activity in vitro and hepatoprotective effect on acute alcohol-induced liver injury in mice of polysaccharides from the peduncles of Hovenia dulcis," Food and Chemical Toxicology, vol. 50, no. 9, pp. 29642970, 2012.

[13] J. Y. Park, J. Y. Moon, S. D. Park, W. H. Park, H. Kim, and J. E. Kim, "Fruits extracts of Hovenia dulcis Thunb. suppresses lipopolysaccharide-stimulated inflammatory responses through nuclear factor-kappaB pathway in Raw 264.7 cells," Asian Pacific Journal of Tropical Medicine, vol. 9, no. 4, pp. 357-365, 2016.

[14] Q. S. Wang, Y. Xiang, Y. L. Cui, K. M. Lin, and X. F. Zhang, "Dietary blue pigments derived from genipin, attenuate inflammation by inhibiting LPS-induced iNOS and COX-2 expression via the NF- $\kappa \mathrm{B}$ inactivation," PLoS One, vol. 7, no. 3, article e34122, p. 11, 2012.

[15] Y. C. Oh, Y. H. Jeong, W. K. Cho, J. H. Ha, S. J. Lee, and J. Y. Ma, "Inhibitory effects of Epimedium herb on the inflammatory response in vitro and in vivo," American Journal of Chinese Medicine, vol. 43, no. 05, pp. 953-968, 2015.

[16] H. J. Choi, O. H. Kang, P. S. Park et al., "Mume Fructus water extract inhibits pro-inflammatory mediators in 
lipopolysaccharide-stimulated macrophages," Journal of Medicinal Food, vol. 10, no. 3, pp. 460-466, 2007.

[17] Y. H. Jeong, Y. C. Oh, W. K. Cho, N. H. Yim, and J. Y. Ma, "Anti-inflammatory effect of Rhapontici Radix ethanol extract via inhibition of NF- $\kappa \mathrm{B}$ and MAPK and induction of $\mathrm{HO}-1$ in macrophages," Mediators of Inflammation, vol. 2016, Article ID 7216912, 13 pages, 2016.

[18] Y. Fu, B. Liu, J. Liu et al., "Geniposide, from Gardenia jasminoides Ellis, inhibits the inflammatory response in the primary mouse macrophages and mouse models," International Immunopharmacology, vol. 14, no. 4, pp. 792-798, 2012.

[19] J. S. Park, I. S. Kim, S. U. Rehman, C. S. Na, and H. H. Yoo, "HPLC determination of bioactive flavonoids in Hovenia dulcis fruit extracts," Journal of Chromatographic Science, vol. 54, no. 2, pp. 130-135, 2016.

[20] L. Samavati, R. Rastogi, W. Du, M. Hüttemann, A. Fite, and L. Franchi, "STAT3 tyrosine phosphorylation is critical for interleukin 1 beta and interleukin-6 production in response to lipopolysaccharide and live bacteria," Molecular Immunology, vol. 46, no. 8-9, pp. 1867-1877, 2009.

[21] R. E. Sacco, W. R. Waters, K. M. Rudolph, and M. L. Drew, "Comparative nitric oxide production by LPS-stimulated monocyte-derived macrophages from Ovis canadensis and Ovis aries," Comparative Immunology, Microbiology and Infectious Diseases, vol. 29, no. 1, pp. 1-11, 2006.

[22] J. R. Vane, "Inhibition of prostaglandin synthesis as a mechanism of action for aspirin-like drugs," Nature New Biology, vol. 231, no. 25, pp. 232-235, 1971.

[23] N. R. Chapman and N. D. Perkins, "Inhibition of the RelA(p65) NF- $\kappa$ B subunit by Egr-1," Journal of Biological Chemistry, vol. 275, no. 7, pp. 4719-4725, 2000.

[24] G. L. Johnson and R. Lapadat, "Mitogen-activated protein kinase pathways mediated by ERK, JNK, and p38 protein kinases," Science, vol. 298, no. 5600, pp. 1911-1912, 2002.

[25] M. Endale, S. C. Park, S. Kim et al., "Quercetin disrupts tyrosine-phosphorylated phosphatidylinositol 3-kinase and myeloid differentiation factor- 88 association, and inhibits MAPK/AP-1 and IKK/NF- $\kappa$ B-induced inflammatory mediators production in RAW 264.7 cells," Immunobiology, vol. 218, no. 12, pp. 1452-1467, 2013.

[26] R. Zenz, R. Eferl, C. Scheinecker et al., "Activator protein 1 (Fos/Jun) functions in inflammatory bone and skin disease," Arthritis Research and Therapy, vol. 10, no. 1, p. 201, 2008.

[27] P. J. Barnes and M. Karin, "Nuclear factor- $\kappa \mathrm{B}$ - a pivotal transcription factor in chronic inflammatory diseases," The New England Journal of Medicine, vol. 336, no. 15, pp. 1066-1071, 1997.

[28] M. Guha and N. Mackman, "LPS induction of gene expression in human monocytes," Cellular Signalling, vol. 13, no. 2, pp. 85-94, 2001.

[29] D. Guo, J. R. Li, Y. Wang, L. S. Lei, C. L. Yu, and N. N. Chen, "Cyclovirobuxinum D suppresses lipopolysaccharide-induced inflammatory responses in murine macrophages in vitro by blocking JAK-STAT signaling pathway," Acta Pharmacologica Sinica, vol. 35, no. 6, pp. 770-778, 2014.

[30] J. N. Ihle, "The Stat family in cytokine signaling," Current Opinion in Cell Biology, vol. 13, no. 2, pp. 211-217, 2001.

[31] B. G. Jung, X. Wang, N. Yi, J. Ma, J. Turner, and B. Samten, "Early secreted antigenic target of 6-kDa of Mycobacterium tuberculosis stimulates IL-6 production by macrophages through activation of STAT3," Scientific Reports, vol. 7, no. 1, article 40984, p. 14, 2017.

[32] L. Weng, H. Zhang, X. Li et al., "Ampelopsin attenuates lipopolysaccharide-induced inflammatory response through the inhibition of the NF- $\kappa \mathrm{B}$ and JAK2/STAT3 signaling pathways in microglia," International Immunopharmacology, vol. 44, pp. 1-8, 2017.

[33] S. Qi, Y. Xin, Y. Guo et al., "Ampelopsin reduces endotoxic inflammation via repressing ROS-mediated activation of PI3K/Akt/NF- $\kappa \mathrm{B}$ signaling pathways," International Immunopharmacology, vol. 12, no. 1, pp. 278-287, 2012.

[34] K. Manigandan, D. Manimaran, R. L. Jayaraj, N. Elangovan, V. Dhivya, and A. Kaphle, "Taxifolin curbs NF- $\kappa$ B-mediated Wnt/ $\beta$-catenin signaling via up-regulating Nrf2 pathway in experimental colon carcinogenesis," Biochimie, vol. 119, pp. 103-112, 2015.

[35] S. Chen and B. Fan, "Myricetin protects cardiomyocytes from LPS-induced injury," Herz, vol. 43, no. 3, pp. 265-274, 2018.

[36] D. H. Lee and C. S. Lee, "Flavonoid myricetin inhibits TNF- $\alpha$-stimulated production of inflammatory mediators by suppressing the Akt, mTOR and NF- $\kappa \mathrm{B}$ pathways in human keratinocytes," European Journal of Pharmacology, vol. 784, pp. 164-172, 2016.

[37] B. O. Cho, H. H. Yin, S. H. Park, E. B. Byun, H. Y. Ha, and S. I. Jang, "Anti-inflammatory activity of myricetin from Diospyros lotus through suppression of NF- $\kappa \mathrm{B}$ and STAT1 activation and Nrf2-mediated HO-1 induction in lipopolysaccharidestimulated RAW264.7 macrophages," Bioscience, Biotechnology, and Biochemistry, vol. 80, no. 8, pp. 1520-1530, 2016. 


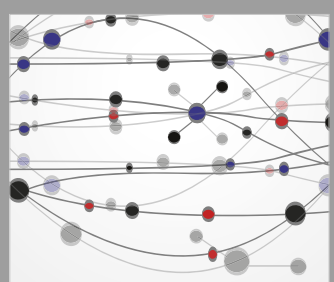

The Scientific World Journal
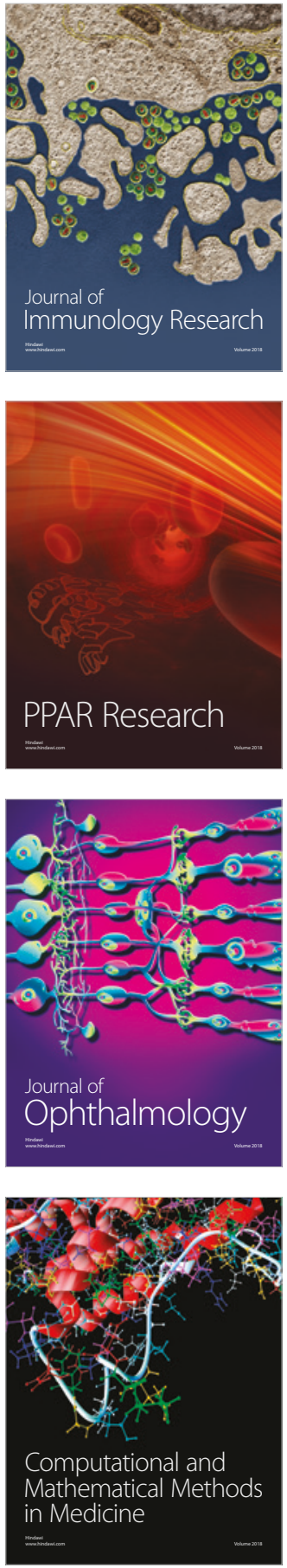

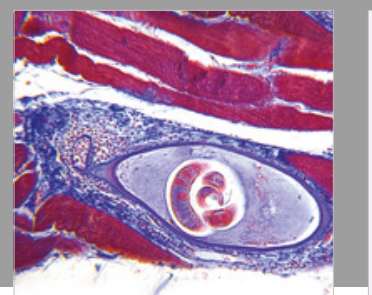

Gastroenterology Research and Practice

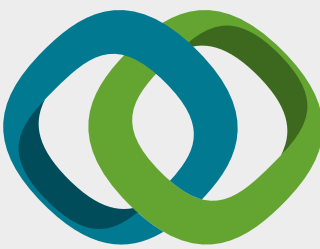

\section{Hindawi}

Submit your manuscripts at

www.hindawi.com
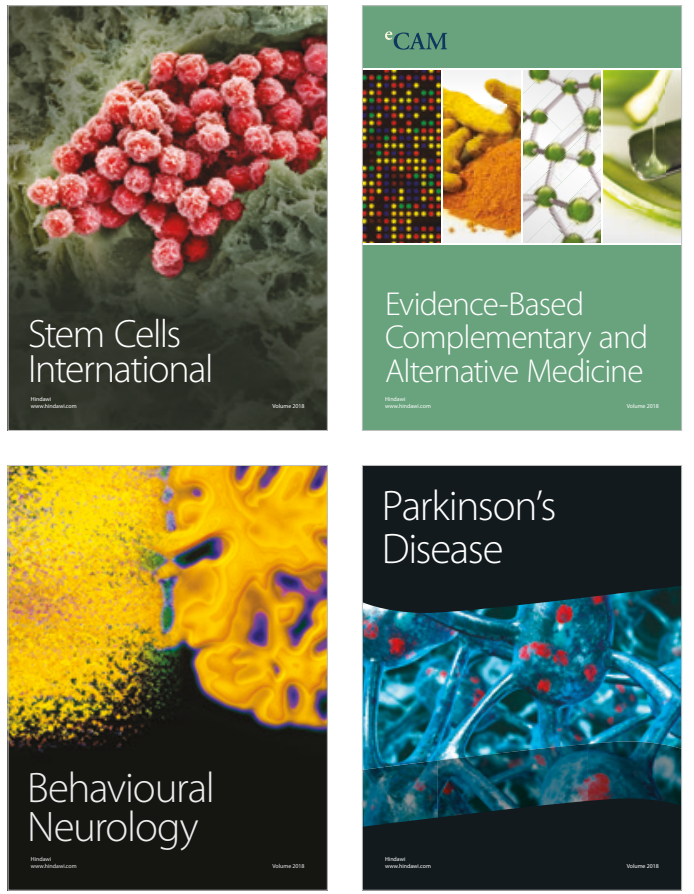

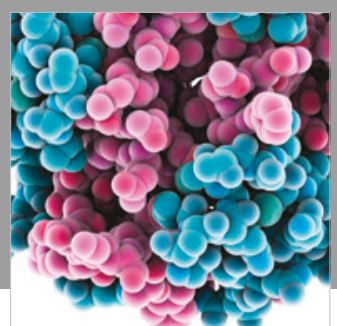

ournal of

Diabetes Research

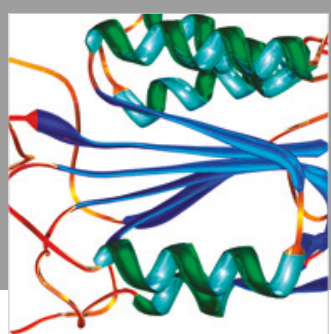

Disease Markers
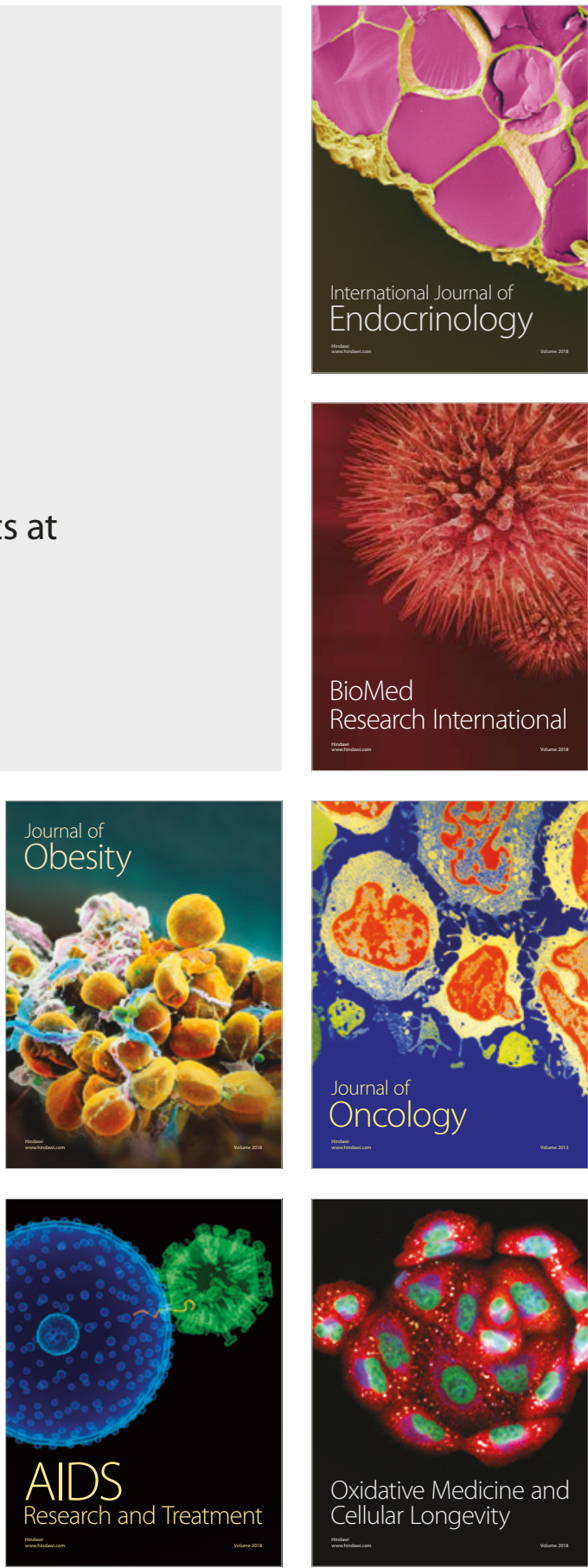